Article

\title{
Energy and Exergy Analysis of High Temperature Agent Gasification of Biomass
}

\author{
Yueshi Wu *, Weihong Yang and Wlodzimierz Blasiak \\ Division of Energy and Furnace Technology, Department of Material Science and Engineering, \\ School of Industrial Engineering and Management, KTH-Royal Institute of Technology, \\ Brinellvägen 23, 10044 Stockholm, Sweden; E-Mails: weihong@kth.se (W.Y.); \\ blasiak@kth.se (W.B.) \\ * Author to whom correspondence should be addressed; E-Mail: yueshiw@kth.se; \\ Tel.: +46-8790-9022.
}

Received: 21 January 2014; in revised form: 6 March 2014 / Accepted: 18 March 2014 / Published: 1 April 2014

\begin{abstract}
A chemical equilibrium model was developed to predict the product composition of a biomass gasification system using highly preheated air and steam. The advantages and limitations of this system were discussed from a thermodynamic viewpoint. The first and second law analyses have been conducted for various preheating temperatures and steam/biomass mass $(\mathrm{S} / \mathrm{B})$ ratios. The results demonstrated that the chemical energy output of the produced syngas is highest when the $\mathrm{S} / \mathrm{B}$ ratio is 1.83 under the conditions used in this study. However, higher S/B ratios have a negative effect on the energy and exergy efficiencies. Higher preheating temperatures increase the chemical energy of the produced syngas and the two efficiencies. The peak values for the energy and exergy efficiencies are $81.5 \%$ and $76.2 \%$, respectively. Based on the calculated limitation values, where the highest chemical energy (exergy) of the produced syngas and maximum achievable efficiencies are determined, a thermodynamically possible operating region is suggested.
\end{abstract}

Keywords: biomass gasification; high temperature agent; Aspen model; exergy

\section{Introduction}

As one of the most promising technologies for the thermochemical conversion of biomass fuels, high temperature agent gasification (HTAG) using highly preheated oxidizing agents such as oxygen, 
air, steam, or a combination thereof has been studied for decades and has been proven to produce a fuel gas with relatively high chemical energy content [1-6], where additional heat provided into the gasification process enhances the decomposition of solid fuel and the cracking of volatiles. Among oxidizing agents, steam gasification provides fuel gas with medium lower heating values (LHV) of $10-16 \mathrm{MJ} / \mathrm{Nm}^{3}$ [7], which is higher than those from air gasification, while being less costly than oxygen gasification. A high $\mathrm{H}_{2}$ yield could be obtained by supplying steam, but it would be at the cost of system efficiency, as the steam gasification is endothermic and consumes large amounts of energy. Using air mixed with steam as a gasifying agent is a common technique for replacing pure steam gasification, where energy required for gasification can be supplied by the partial combustion of biomass with air [8].

Past research has focused on the thermodynamics of HTAG process to determine whether biomass can be gasified efficiently from an energy-saving perspective. Apart from energy, exergy is another key factor to evaluate the potential efficiency of a process. For example, the energy efficiency of electric motors can reach up to $90 \%$, and thus it is impossible to achieve further improvement [9]. Theoretically, exergy analysis based on the second law of thermodynamics could give a better explanation, that the performance of engineering systems is degraded by the presence of irreversibility. Therefore, for industrial applications, exergy conscious utilization is an essential method in resource-saving and efficient production. A detailed investigation of the energy and exergy efficiencies of HTAG process was presented for air gasification [10,11], revealing that the optimal air preheating temperature causes the gasification to occur at the carbon boundary point (CBP), where all carbon is consumed. Ponzio et al. [12] discussed the advantages and limitations of an auto-thermal HTAG system using biomass and air, noting that the use of an additional preheating system to preheat the gasification air beyond what is possible by the heat exchange between hot syngas and air allows a denser syngas to be produced in terms of both energy and exergy. Zhang et al. [13] concluded that steam gasification is superior by comparing the energy and exergy efficiencies with air gasification in HTAG process from $800{ }^{\circ} \mathrm{C}$ to $1200{ }^{\circ} \mathrm{C}$; meanwhile, higher efficiencies can be achieved for both technologies by increasing the gasification temperature. However, more research is still needed on steam/air mixture gasification, such as the determination of peak values for preheating temperature and steam feeding (if they exist) and their effects on efficiency in terms of energy and exergy.

An industrial scale gasifier constitutes a large financial investment, and may cause safety problems in some cases. Therefore numerous models have been developed to cost-effectively evaluate design parameters. These models can be classified into 0-D (dimension), 1-D, 2-D and 3-D models, in terms of dimensional coordinates used. Among these models, 1-D models are the most commonly used by researchers [14,15]. 2-D and 3-D models involve spatial variables considering the flow fields inside in addition to kinetic mechanism, which require huge computational effort, making them a harsh choice for gasifier design. In contrast to 1-D, 2-D and 3-D models, 0-D one is independent of gasifier geometry. It is referred to as a thermodynamic equilibrium model, where the examined system is assumed to have reached a stable composition, with minimizing Gibbs free energy. It has been proven to be reliable to predict the complete conversion of biomass and the theoretical efficiency by many researchers [16-21]. The equilibrium model is applicable in the present work, since high operating temperature permits fast reaction chemistry during the residence time. Therefore, a five-step equilibrium model was built for a downdraft fixed-bed gasifier in HTAG process using ASPEN PLUS process simulation software 
(Burlington, MA, USA). Both first and second law analyses have been conducted by modeling the gasifier as an equilibrium reactor for various steam/biomass mass $(\mathrm{S} / \mathrm{B})$ ratios and preheating temperatures. Finally, a thermodynamically possible operating region was suggested by calculating the thermodynamic limitations of the HTAG process.

\section{Facility and Feedstock}

\subsection{Experimental Setup}

A demonstration scale HTAG test facility was constructed at KTH-Royal Institute of Technology, (Stockholm, Sweden). The system was described in a previous publication [22], and a general description is given here. The feedstock was filled from the top of a vertically cylindrical reactor by a continuous feeding system with four synchronize screws. The gasifying agent (air/steam mixture) was preheated to $1000{ }^{\circ} \mathrm{C}$ by a regenerative preheater and then introduced into the reactor from the side. The grate stopped biomass/char particles, resulting in a charcoal bed. The pyrolyzed gases mixed with the gases produced by combustion passed through the grate and generated produced gases, which were sampled at the outlet of the gasifier. The temperatures were measured using thermocouple probes located in the center line along the reactor's height in different reaction zones. The gasifier was run at the atmospheric pressure. The scheme of the HTAG system is presented in Figure 1.

Figure 1. Scheme of the high temperature agent gasification (HTAG) system at KTH-Royal Institute of Technology.

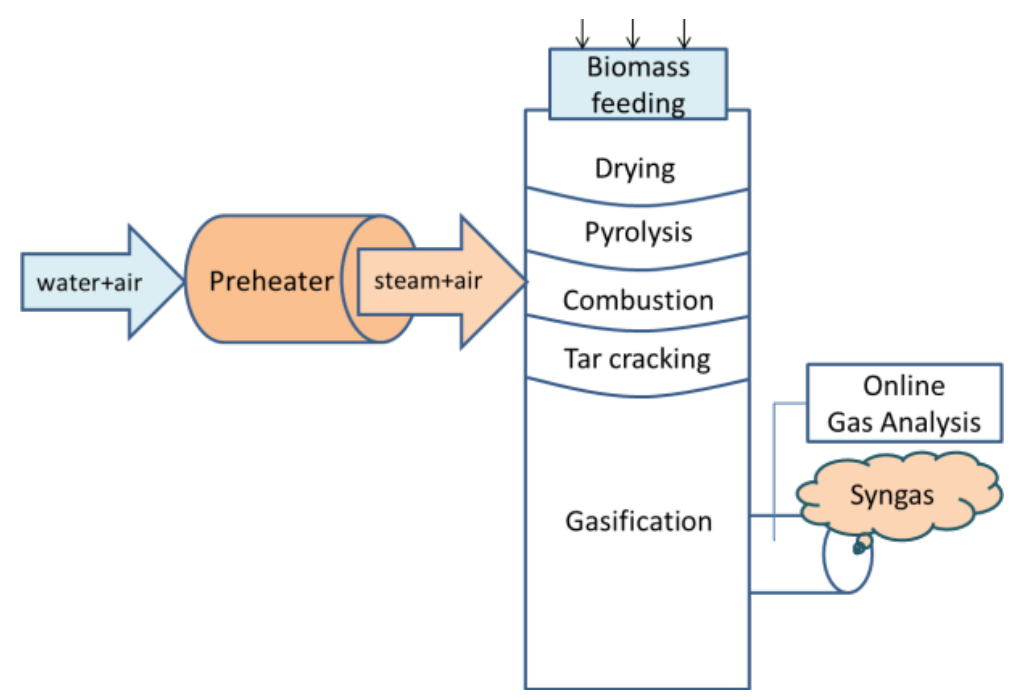

\subsection{Fuel Parameters}

The biomass used for the experiment was wood pellets with a diameter of $0.008 \mathrm{~m}$ and an average ratio of length/diameter, $l / d$, of 4 . The properties of the feedstock are shown in Table 1 . The feedstock was supplied and analyzed by an external supplier, Booforssjö Energi AB, Katrineholm, Sweden. 
Table 1. Characterization of the biomass feedstock.

\begin{tabular}{cccccc}
\hline Proximate analysis & & & \multicolumn{2}{c}{ Ultimate analysis (dry basis) } \\
\cline { 1 - 2 } \cline { 5 - 5 } Moisture (\%) & 8 & & $\mathrm{C}(\%)$ & 50 \\
Volatile (\%, dry basis) & 84 & & $\mathrm{H}(\%)$ & $6.0-6.2$ \\
Fixed carbon (\%, dry basis) & 15.5 & & $\mathrm{O}(\%)$ & $43-44$ \\
Ash (\%, dry basis) & 0.5 & & $\mathrm{~N}(\%)$ & $<0.2$ \\
- & - & & $\mathrm{S}(\%)$ & $0.01-0.02$ \\
\hline
\end{tabular}

\section{Methodology}

\subsection{Model Description}

In this study, a steady-state model of HTAG process was developed with the chemical process simulator ASPEN PLUS. Figure 2 shows the ASPEN PLUS flow sheet for the HTAG system. Five different stages were considered in the ASPEN PLUS simulation: drying, pyrolysis, combustion, tar cracking and gasification. The process was assumed to be adiabatic and under chemical equilibrium. All gases were ideal.

Figure 2. ASPEN PLUS flow sheet for the HTAG process.

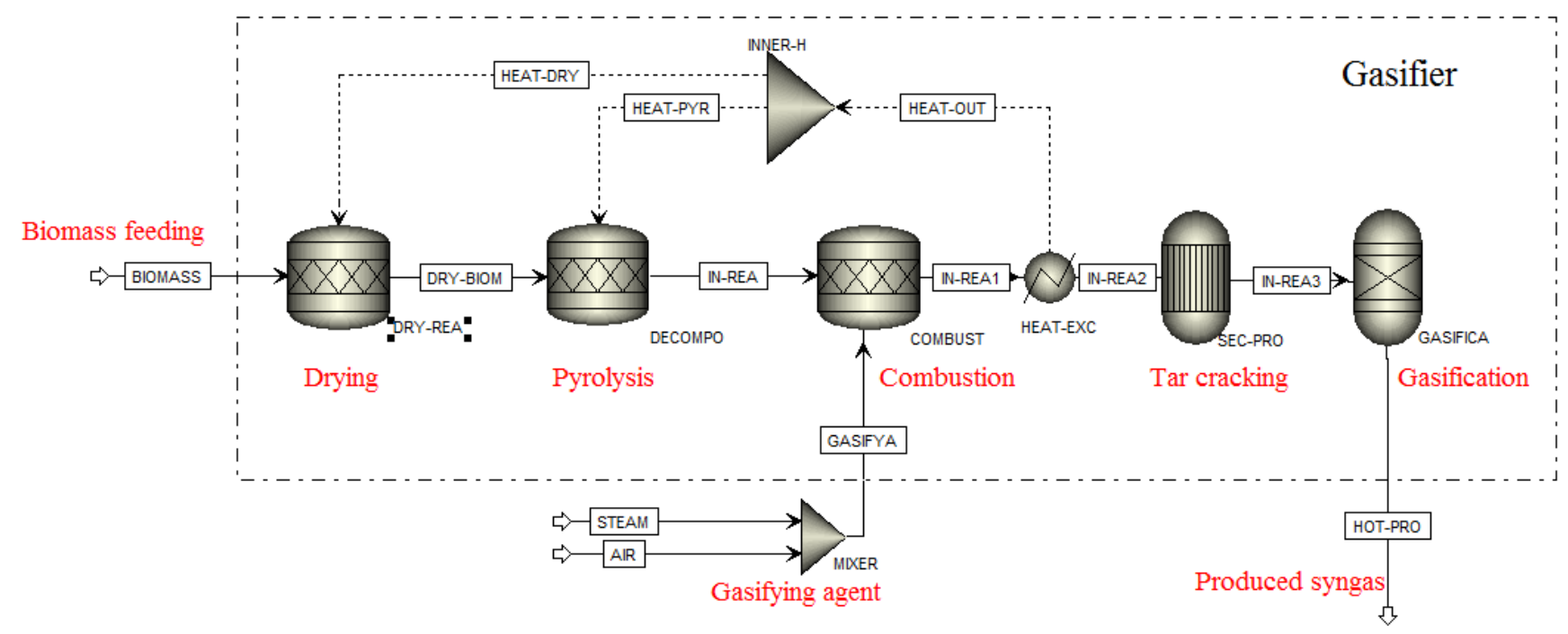

\subsubsection{Drying}

The drying reaction occurs when the raw biomass meets the hot environment in the DRY-REA reactor in the first stage. The moisture content is assumed to be removed completely and converted into steam at $101^{\circ} \mathrm{C}$ :

$$
\text { Biomass (wet) } \rightarrow \text { Biomass (dry) }+\mathrm{H}_{2} \mathrm{O} \text { (steam) }
$$

\subsubsection{Biomass Pyrolysis}

An RStoic reactor was used to describe the pyrolysis of biomass. In this stage, dry biomass is converted into char, ash, tar and small molecular gases: $\mathrm{CO}, \mathrm{CO}_{2}, \mathrm{H}_{2}, \mathrm{H}_{2} \mathrm{O}$ and $\mathrm{CH}_{4}$ : 


$$
\text { Biomass (dry) } \rightarrow \text { char }+ \text { ash }+\alpha_{1} \mathrm{CO}+\alpha_{2} \mathrm{CO}_{2}+\alpha_{3} \mathrm{H}_{2}+\alpha_{4} \mathrm{H}_{2} \mathrm{O}+\alpha_{5} \mathrm{CH}_{4}+\alpha_{6} \text { tar }
$$

Char is assumed to be pure carbon. The yields of char and ash were calculated by proximate analysis of the biomass. $\alpha_{1}, \alpha_{2}, \alpha_{3}, \alpha_{4}$ and $\alpha_{5}$ are the stoichiometric coefficients of $\mathrm{CO}, \mathrm{CO}_{2}, \mathrm{H}_{2}$, $\mathrm{H}_{2} \mathrm{O}$ and $\mathrm{CH}_{4}$, respectively. They are estimated based on literature data [23] obtained for wood. The composition of tar is determined by the tar cracking reaction, and the stoichiometric coefficient of tar, $\alpha_{6}$, is calculated by the elemental balance of the biomass pyrolysis reaction.

\subsubsection{Combustion}

The char content was partially oxidized to yield the combustion product $\mathrm{CO}$, plus heat to the endothermic reactions in the reactor. The RStoic reactor was used in this stage. It was assumed that the oxygen was completely consumed:

$$
\text { char }+\mathrm{O}_{2} \rightarrow \mathrm{CO}
$$

\subsubsection{Tar Cracking}

The RYield reactor was used to describe the tar cracking reaction. The residual tar continues to decompose into small molecular gases: $\mathrm{CO}, \mathrm{CO}_{2}, \mathrm{H}_{2}$ and $\mathrm{CH}_{4}$ :

$$
\operatorname{tar} \rightarrow \beta_{1} \mathrm{CO}+\beta_{2} \mathrm{CO}_{2}+\beta_{3} \mathrm{H}_{2}+\beta_{4} \mathrm{CH}_{4}
$$

Tar is a complex mixture of hundreds of different organic species; however, the global composition is used by calculating the elemental balance of the tar cracking reaction. $\beta_{1}, \beta_{2}, \beta_{3}$, and $\beta_{4}$ are the stoichiometric coefficients of $\mathrm{CO}, \mathrm{CO}_{2}, \mathrm{H}_{2}$ and $\mathrm{CH}_{4}$, respectively. They were estimated using experimental data taken from the literature [24].

The final tar yield is controlled by the empirical relation [25] as follows:

$$
Y_{\mathrm{tar}}=35.98 \exp (-0.0029 T)
$$

In this equation, $T$ is global temperature in the tar cracking zone in ${ }^{\circ} \mathrm{C}$.

\subsubsection{Gasification}

The gasification section is expressed by a Gibbs reactor, which calculates the chemical equilibrium by minimizing the Gibbs free energy.

Because the reforming reaction rate of $\mathrm{CH}_{4}$ is slow, the $\mathrm{CH}_{4}$ content in syngas is much higher than what the methane equilibrium suggests, which corresponds to concentrations well below $1 \%$. A sub-model was set up in the Gibbs reactor to express the $\mathrm{CH}_{4}$ yield by an empirical expression [26]:

$$
\begin{gathered}
\alpha=\frac{\mathrm{CH}_{4}}{\mathrm{CH}_{4}+\mathrm{CO}+\mathrm{CO}_{2}} \\
\alpha=0.0052 \cdot \exp \left(\frac{3960}{T+273.15}\right) \cdot P^{0.149}
\end{gathered}
$$

where $\alpha$ is the mole fraction of $\mathrm{CH}_{4}$ relative to total $\mathrm{CH}_{4}, \mathrm{CO}$, and $\mathrm{CO}_{2} . T$ and $P$ are the global temperature and pressure in the gasification section, respectively. 


\subsection{Energy and Exergy Balances}

\subsubsection{Energy Balance}

According to the first law of thermodynamics, which describes energy balance, if the heat loss of the HTAG system is neglected, the energy distribution in the system is:

$$
\Sigma_{\text {in }} H=\Sigma_{\text {out }} H
$$

where $\Sigma_{\text {in }} H$ and $\Sigma_{\text {out }} H$ are the enthalpies of all streams entering and leaving, respectively.

Considering the chemical energy of the produced syngas as the target product, the global energy efficiency of the HTAG process can be defined as:

$$
\eta_{\text {energy }}=\frac{m_{\text {gas }} L H V_{\text {gas }}}{m_{\text {biomass }} L H V_{\text {biomass }}+H_{\text {agent }}}
$$

where $m_{\text {biomass }}$ and $m_{\text {gas }}$ are the mass flow rates of biomass and produced syngas, $\mathrm{kg} / \mathrm{s} ; L H V_{\text {biomass }}$ $\left(17.76 \mathrm{MJ} / \mathrm{kg}\right.$ ) and $L H V_{\text {gas }}$ are the lower heating values of biomass and produced syngas, respectively; and $H_{\text {agent }}$ is the energy flow supplied by the high temperature gasifying agent.

\subsubsection{Exergy Balance}

The exergy does not obey a conservation law due to irreversibility, which represents the quality losses of materials and energy caused by dissipation. The corresponding exergy balance of a steady-state process obeys the equation:

$$
E x_{\text {biomass }}+E x_{\text {agent }}=E x_{\text {gas }}+E x_{\text {tar }}+E x_{\text {ash }}+I
$$

where $E x_{\text {biomass, }} E x_{\text {agent, }} E x_{\text {gas }}, E x_{\text {tar }}$ and $E x_{\text {ash }}$ indicate the exergy of the biomass, gasifying agent, produced syngas, tar and ash, respectively; and $I$ represents the irreversibility.

The exergy in a material stream can be calculated as the sum of its chemical exergy $E x^{\text {ch }}$ and physical exergy $E x^{\text {ph }}$ :

$$
E x=E x^{\mathrm{ch}}+E x^{\mathrm{ph}}
$$

The kinetic and other types of exergies are neglected. The physical exergy of the gaseous material and char are calculated as:

$$
E x^{\mathrm{ph}}=\sum_{i} x_{i} e x_{i}^{\mathrm{ph}}
$$

where $i$ indicates the gas component or char; $x_{i}$ and $e x_{i}^{\mathrm{ph}}$ are the mole flow rate and physical exergy of component $i$, respectively.

For each component, the physical exergy is defined as:

$$
\begin{gathered}
E x^{\mathrm{ph}}=\left(h-h_{0}\right)-T_{0}\left(s-s_{0}\right) \\
h-h_{0}=\int_{T_{0}}^{T} c_{\mathrm{p}} \mathrm{d} T
\end{gathered}
$$




$$
\mathrm{s}-\mathrm{s}_{0}=\int_{T_{0}}^{T} \frac{c_{\mathrm{p}}}{T} \mathrm{~d} T
$$

where $h$ and $s$ are the specific enthalpy and entropy, respectively, in the specified state characterized by temperature $T ; h_{0}$ and $s_{0}$ denote the enthalpy and entropy, respectively, under the environmental condition with temperature $T_{0}(298 \mathrm{~K})$ and a pressure of $1 \mathrm{~atm}$; and $c_{\mathrm{p}}$ is the constant pressure specific heat capacity, $\mathrm{kJ} / \mathrm{kmol} \cdot \mathrm{K}$, which is given in Table 2 .

Table 2. Constant pressure specific heat capacity of some species.

\begin{tabular}{ccc}
\hline Species & $c_{\mathrm{p}}(\mathbf{k J} / \mathbf{k m o l} \cdot \mathbf{K})$ & Reference \\
\hline $\mathrm{N}_{2}$ & $c_{\mathrm{p}}=39.060-512.79\left(\frac{T}{100}\right)^{-1.5}+1072.7\left(\frac{T}{100}\right)^{-2}-820.4\left(\frac{T}{100}\right)^{-3}$ & {$[27]$} \\
$\mathrm{O}_{2}$ & $c_{\mathrm{p}}=25.48+1.52 \times 10^{-2} T-0.7155 \times 10^{-5} T^{2}+1.312 \times 10^{-9} T^{3}$ & {$[28]$} \\
$\mathrm{H}_{2} \mathrm{O}(\mathrm{g})$ & $c_{\mathrm{p}}=32.24+0.1923 \times 10^{-2} T+1.055 \times 10^{-5} T^{2}-3.595 \times 10^{-9} T^{3}$ & {$[28]$} \\
$\mathrm{CO}$ & $c_{\mathrm{p}}=28.16+0.1675 \times 10^{-2} T+0.5327 \times 10^{-5} T^{2}-2.222 \times 10^{-9} T^{3}$ & {$[28]$} \\
$\mathrm{CO}_{2}$ & $c_{\mathrm{p}}=22.26+5.981 \times 10^{-2} T-3.501 \times 10^{-5} T^{2}+7.469 \times 10^{-9} T^{3}$ & {$[28]$} \\
$\mathrm{H}_{2}$ & $c_{\mathrm{p}}=29.11-0.1916 \times 10^{-2} T+0.4003 \times 10^{-5} T^{2}-0.8704 \times 10^{-9} T^{3}$ & {$[28]$} \\
$\mathrm{CH}_{4}$ & $c_{\mathrm{p}}=18.89+5.024 \times 10^{-2} T+1.269 \times 10^{-5} T^{2}-11.01 \times 10^{-9} T^{3}$ & {$[28]$} \\
$\mathrm{Char}$ & $c_{\mathrm{p}}=17.166+4.271 \frac{T}{1000}-\frac{8.79 \times 10^{5}}{T^{2}}$ & {$[29]$} \\
\hline
\end{tabular}

The chemical exergy can be calculated by:

$$
E x^{\mathrm{ch}}=\sum_{i} x_{i}\left(e x_{i}^{\mathrm{ch}}+\mathrm{R} T_{0} \ln \frac{x_{i}}{\sum x_{i}}\right)
$$

where $e x_{i}^{\mathrm{ch}}$ is the standard chemical exergy of gaseous component $i$; and $R$ is the universal gas contant, $8.314 \mathrm{~kJ} / \mathrm{kmol} \cdot \mathrm{K}$.

The values of the specific enthalpy, entropy and standard chemical exergy of gaseous components are given in Table 3. The chemical exergy of char is $410,260 \mathrm{~kJ} / \mathrm{kmol}$ [30].

Table 3. Specific enthalpy, entropy and standard chemical exergy values of gaseous components $[28,30]$.

\begin{tabular}{cccc}
\hline Component & $\boldsymbol{h}_{\mathbf{0}}(\mathbf{k J} / \mathbf{k m o l})$ & $\boldsymbol{s}_{\mathbf{0}}(\mathbf{k J} / \mathbf{k m o l} \cdot \mathbf{K})$ & $\boldsymbol{e \boldsymbol { x } _ { \boldsymbol { i } } ^ { \mathbf { c h } }}(\mathbf{k J} / \mathbf{k m o l})$ \\
\hline $\mathrm{N}_{2}$ & 0 & 191.61 & 668 \\
$\mathrm{O}_{2}$ & 0 & 205.033 & 3,970 \\
$\mathrm{H}_{2} \mathrm{O}(\mathrm{g})$ & $-228,583$ & 188.720 & 9,500 \\
$\mathrm{CO}$ & $-137,150$ & 197.543 & 275,100 \\
$\mathrm{CO}_{2}$ & $-394,374$ & 213.685 & 19,870 \\
$\mathrm{H}_{2}$ & 0 & 130.574 & 236,100 \\
$\mathrm{CH}_{4}$ & $-74,850$ & 186.16 & 831,650 \\
\hline
\end{tabular}


As the biomass was fed in the environmental state, the physical exergy of the biomass can be neglected. The chemical exergy of the biomass was proposed by Szargut and Styrylska [31]:

$$
E x_{\text {biomass }}=m_{\text {biomass }} \beta L H V_{\text {biomass }}
$$

The formula of correlation factor $\beta$ for wood pellets is given by:

$$
\beta=\frac{1.0414+0.0177\left(\frac{\mathrm{H}}{\mathrm{C}}\right)-0.3328\left(\frac{\mathrm{O}}{\mathrm{C}}\right)\left[1+0.0537\left(\frac{\mathrm{H}}{\mathrm{C}}\right)\right]}{1-0.4021\left(\frac{\mathrm{O}}{\mathrm{C}}\right)}
$$

where $\mathrm{C}, \mathrm{H}$ and $\mathrm{O}$ are the molar fractions of $\mathrm{C}, \mathrm{H}$ and $\mathrm{O}$ in wood pellets, respectively.

Similarly, the chemical exergy of tar can be calculated using the correlation for liquid fuels [32]:

$$
E x_{\mathrm{tar}}^{\mathrm{ch}}=L H V_{\mathrm{tar}}\left[1.0401+0.1728\left(\frac{\mathrm{H}}{\mathrm{C}}\right)+0.0432\left(\frac{\mathrm{O}}{\mathrm{C}}\right)\right]
$$

Similar to energy efficiency, the total exergy efficiency of the HTAG process can be defined as:

$$
\eta_{\text {exergy }}=\frac{E x_{\text {gas }}^{\text {ch }}}{E x_{\text {biomass }}+E x_{\text {agent }}}
$$

\section{Results and Discussion}

\subsection{Comparison with Experimental Data}

The experimental data reported in our previous publication [33] are used for comparison with the simulation results. For the comparison case, the feedstock mass flow rate is $60 \mathrm{~kg} / \mathrm{h}$, and the mass flow rates of steam and air are $50 \mathrm{~kg} / \mathrm{h}$ and $25 \mathrm{~kg} / \mathrm{h}$, respectively. The preheating temperature was measured as $700{ }^{\circ} \mathrm{C}$. The operating pressure was $1 \mathrm{~atm}$.

Table 4 shows the comparison of the model-predicted produced gas parameters with the experimental values. The gas composition, tar content and temperature after gasification were compared. It can be observed that the predicted results fit well with the experimental data. This model is acceptable for predicting the performance of the HTAG (air/steam mixture) process in such kind of downdraft fixed-bed gasifier.

Table 4. Comparison between experimental and simulated results.

\begin{tabular}{ccccc}
\hline Parameters & & Experiment & Simulation & Errors \\
\hline & $\mathrm{H}_{2}$ & 24.80 & 24.95 & $0.61 \%$ \\
Gas composition & $\mathrm{CO}$ & 30.08 & 29.91 & $0.55 \%$ \\
$(\mathrm{~mol} \%$ dry, inert free basis) & $\mathrm{CO}_{2}$ & 38.26 & 38.35 & $0.25 \%$ \\
& $\mathrm{CH}_{4}$ & 6.86 & 6.78 & $1.18 \%$ \\
\hline Tar content $\left(\mathrm{g} / \mathrm{Nm}^{3}\right)$ & & 1.85 & 1.70 & $8.11 \%$ \\
\hline Outlet temperature $\left({ }^{\circ} \mathrm{C}\right)$ & & 880 & 889 & $1.02 \%$ \\
\hline
\end{tabular}




\subsection{Parameter Study}

The performance of the gasifier is directly influenced by the choice of operating conditions. In this study, the examined parameters were S/B ratio and preheating temperature of the gasifying agent. Each operating parameter was varied while the other one was kept constant. For all cases, the mass flow rates of the feedstock and air were $60 \mathrm{~kg} / \mathrm{h}$ and $25 \mathrm{~kg} / \mathrm{h}$, respectively.

\subsubsection{Effect of Supplied Steam}

The S/B ratio has a strong influence on both energy (exergy) input and output. Figure 3 illustrates the energy flow from the HTAG process as a function of $\mathrm{S} / \mathrm{B}$ ratio for $T=1000{ }^{\circ} \mathrm{C}$. As the $\mathrm{S} / \mathrm{B}$ ratio increases from 0 to 2.5 , the total energy input increases from $1094 \mathrm{MJ} / \mathrm{h}$ to $1428 \mathrm{MJ} / \mathrm{h}$. At low $\mathrm{S} / \mathrm{B}$ ratios $(<0.53)$, the oxidized agent is not sufficient to supply energy for a complete gasification, and a large amount of input energy was lost by unreacted char. Until the S/B ratio reaches 0.53 , both the chemical and physical energy of char are $0 \mathrm{MJ} / \mathrm{h}$, indicating that complete char gasification was achieved. In this range, the chemical energy of the produced syngas increases significantly from $659 \mathrm{MJ} / \mathrm{h}$ to $977 \mathrm{MJ} / \mathrm{h}$. When the $\mathrm{S} / \mathrm{B}$ ratio is increased from 0.53 , the chemical energy of the syngas increases quite slowly to a maximum value of $1008 \mathrm{MJ} / \mathrm{h}$ at $\mathrm{S} / \mathrm{B}=1.83$, which is probably because of the enhanced tar cracking reaction. After this point, the chemical energy of syngas remains constant, while the physical energy of the product increases significantly. This finding indicates that the gasification process reaches a maximum balance at $\mathrm{S} / \mathrm{B}=1.83$. Beyond this value, the gasifier will be overfed with steam, and the additional steam will contribute to only the physical energy of the product.

Figure 3. Energy balance of the HTAG process as a function of steam/biomass mass (S/B) ratio for $T=1000^{\circ} \mathrm{C}$.

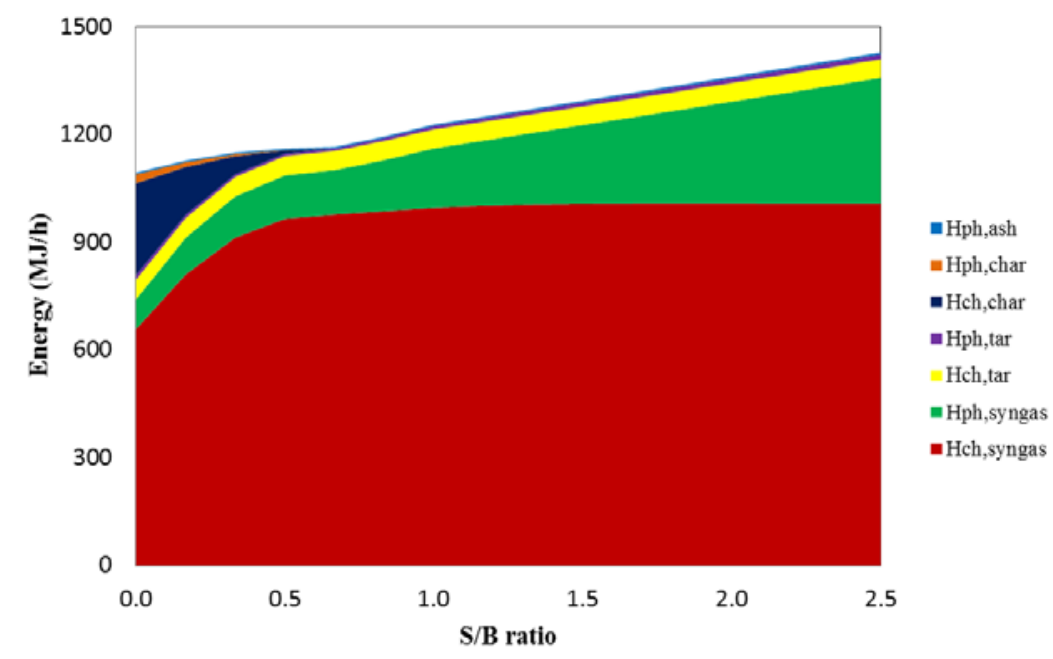

Figure 4 shows the exergy balance of the HTAG process as a function of $\mathrm{S} / \mathrm{B}$ ratio for $T=1000{ }^{\circ} \mathrm{C}$. The exergy balance has the same turning point as the energy balance, namely, $\mathrm{S} / \mathrm{B}=0.53$, at which point the added steam is just sufficient for complete char gasification and the chemical exergy of the syngas is $974 \mathrm{MJ} / \mathrm{h}$. The exergy balance differs from the energy balance in the exergy loss due to irreversibility. The exergy loss by irreversibility decreases from $90 \mathrm{MJ} / \mathrm{h}$ to $59 \mathrm{MJ} / \mathrm{h}$ when $\mathrm{S} / \mathrm{B}$ ratio increases from 0 to 0.53 . Beyond this point, irreversibility increases quite slowly until the system 
reaches the maximum balance at $\mathrm{S} / \mathrm{B}=1.83$. When the $\mathrm{S} / \mathrm{B}$ ratio continues to increase, the exergy loss increases significantly, which is mainly due to the increasing internal entropy generation.

Figure 4. Exergy balance of the HTAG process as a function of $\mathrm{S} / \mathrm{B}$ ratio for $T=1000^{\circ} \mathrm{C}$.

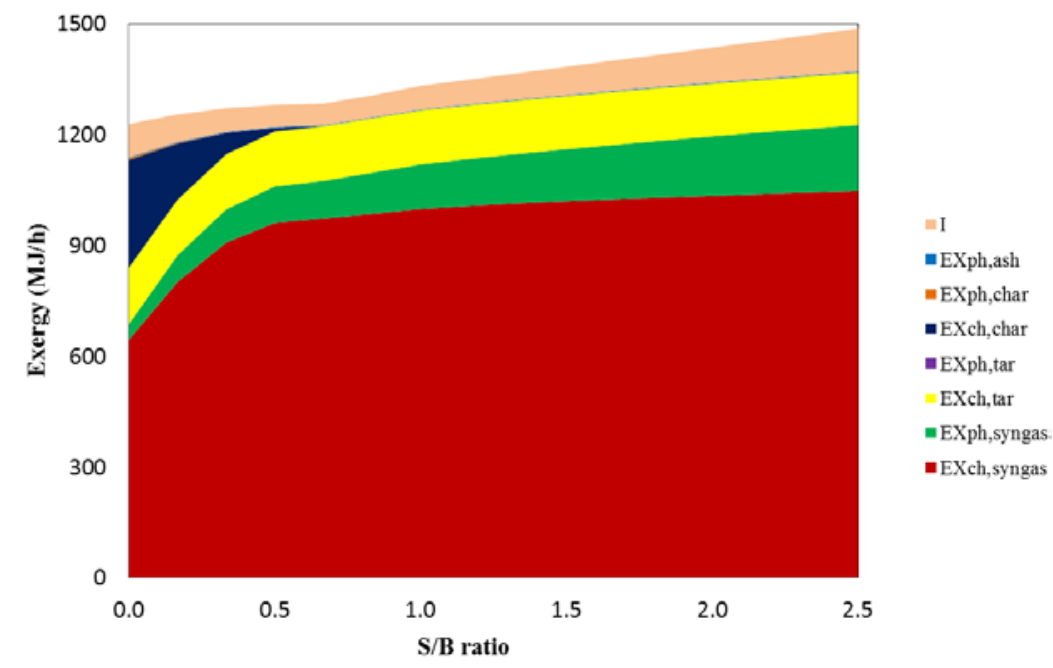

In the HTAG process, adding steam increases the chemical energy and exergy content in the produced syngas. However, adding steam also demands additional energy (exergy). Figure 5 provides the energy and exergy efficiencies as a function of $\mathrm{S} / \mathrm{B}$ for $T=1000{ }^{\circ} \mathrm{C}$ to justify the cost of supplying steam. It shows that both $\eta_{\text {energy }}$ and $\eta_{\text {exergy }}$ increase when the $S / B$ ratio increases from 0 to 0.53 , which is caused by minimizing incomplete char gasification due to an insufficient oxidized agent supply. As the S/B ratio continues to increase, the two efficiencies begin to decrease. Although the chemical energy peaks at $\mathrm{S} / \mathrm{B}=1.83$, the efficiency loss is not completely offset by this benefit. This finding shows that operating at very high S/B ratios may not be energy or exergy efficient. Meanwhile, it can be seen that the exergy efficiency decreases slower than the energy efficiency. It has been discussed that the chemical energy (exergy) has a slow increasing in a high S/B ratio range. If pay attention to the denominator in the definition of energy (exergy) efficiency in the Equation (9) (Equation (20)), it might be explained by the fact that the input chemical exergy of steam keeps increasing while the input chemical energy of steam is always zero.

Figure 5. Energy and exergy efficiencies of the HTAG process as a function of S/B ratio for $T=1000{ }^{\circ} \mathrm{C}$.

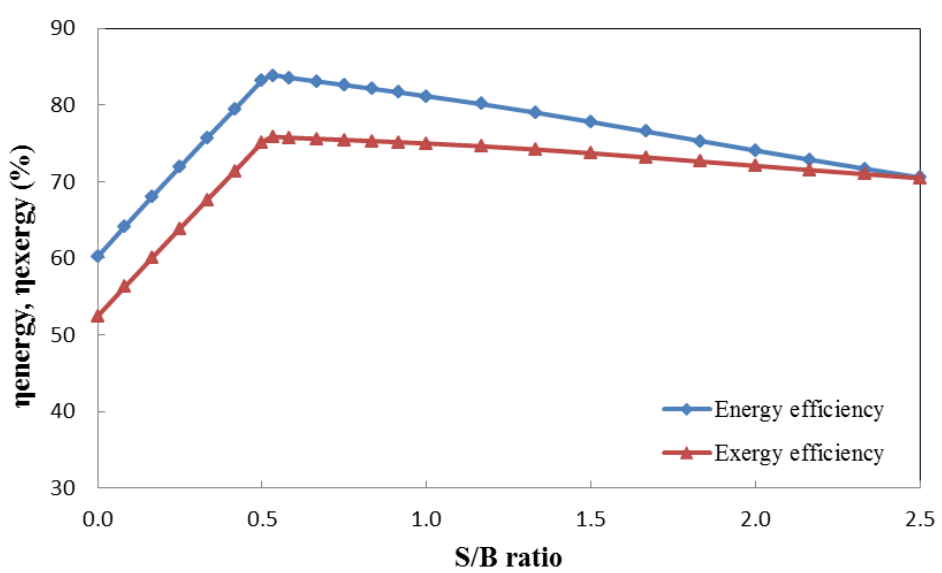




\subsubsection{Effect of Preheating Temperature}

In Figure 6, the energy output from the HTAG process is described as a function of preheating temperature of the gasifying agent under the condition $\mathrm{S} / \mathrm{B}=1.0$ (completely char gasification). This figure shows that the chemical energy of the produced syngas increases from $907 \mathrm{MJ} / \mathrm{h}$ to $1065 \mathrm{MJ} / \mathrm{h}$ with the increase in the preheating temperature of the agent from 650 to $1400{ }^{\circ} \mathrm{C}$. The increasing trend slows down when the preheating temperature reaches $1100{ }^{\circ} \mathrm{C}$. Higher preheating temperatures lead to higher gasification temperatures, which are the reason of the increasing physical energy of syngas. However, the physical energy of tar shows the opposite trend, which is mainly because of the enhanced tar cracking reaction at elevated temperatures, consequently, the tar content decreases. It is also proven by the decreasing chemical energy of tar.

Figure 6. Energy balance of the HTAG process as a function of preheating temperature for $\mathrm{S} / \mathrm{B}=1$.

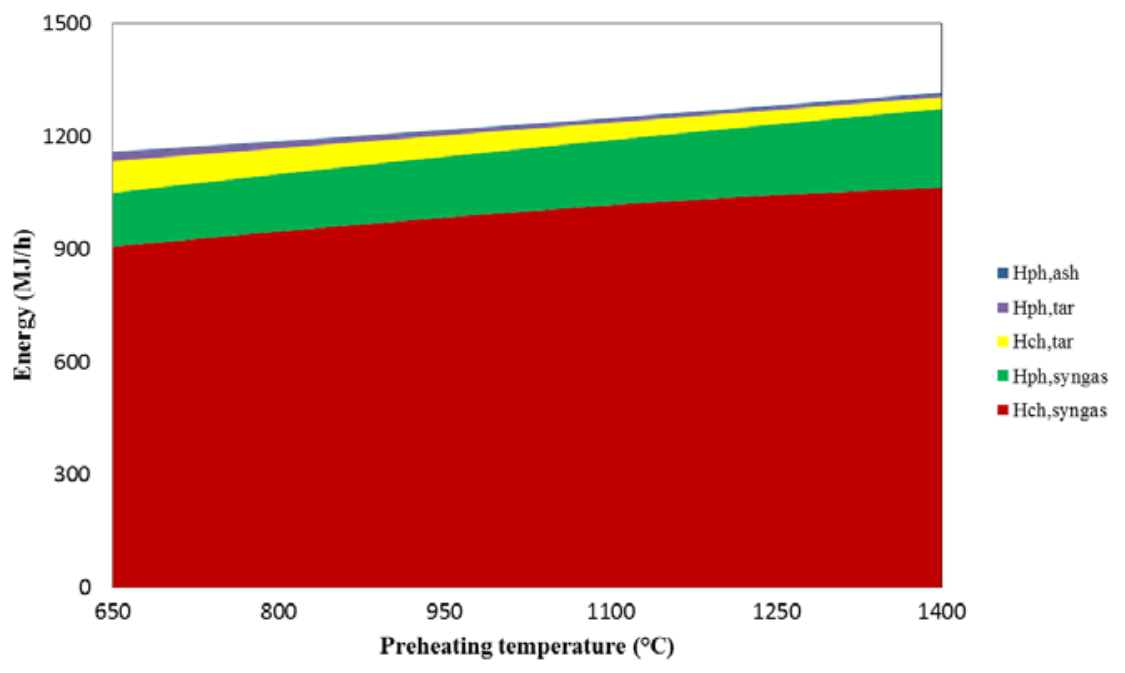

Figure 7 describes the exergy flow of the HTAG process as a function of preheating temperature for $\mathrm{S} / \mathrm{B}=1$, which shows a similar trend as energy flow. Higher preheating temperatures result in higher chemical exergy for syngas and lower exergy content for tar; therefore, HTAG could be considered to improve the gasification process. However, higher preheating temperatures require more energy to achieve and will make greater demands of the equipment as well. Therefore, a proper preheating temperature should be selected based on the material limitations. As observed, there is a linear increase in exergy loss due to irreversibility from $15 \mathrm{MJ} / \mathrm{h}$ to $121 \mathrm{MJ} / \mathrm{h}$, which is due to the internal entropy generation caused by higher temperatures.

The energy and exergy efficiencies as a function of preheating temperature are plotted in Figure 8. In the range of $650{ }^{\circ} \mathrm{C}$ to $1150{ }^{\circ} \mathrm{C}$, the energy efficiency increases with the preheating temperature, reaching a thermodynamical maximum of $81.5 \%$. After the maximum, the energy efficiency decreases. The exergy efficiency increases from $650{ }^{\circ} \mathrm{C}$ to $1350{ }^{\circ} \mathrm{C}$, with a peak value of $76.2 \%$ at $1350{ }^{\circ} \mathrm{C}$.

In both situations, the exergy efficiencies are always less than the energy efficiencies because the second-law efficiency is evaluated after considering the energy loss caused by irreversibility, whereas the first-law efficiency merely considers the ratio of useful energy to total energy input. 
Figure 7. Exergy balance of the HTAG process as a function of preheating temperature for $\mathrm{S} / \mathrm{B}=1$.

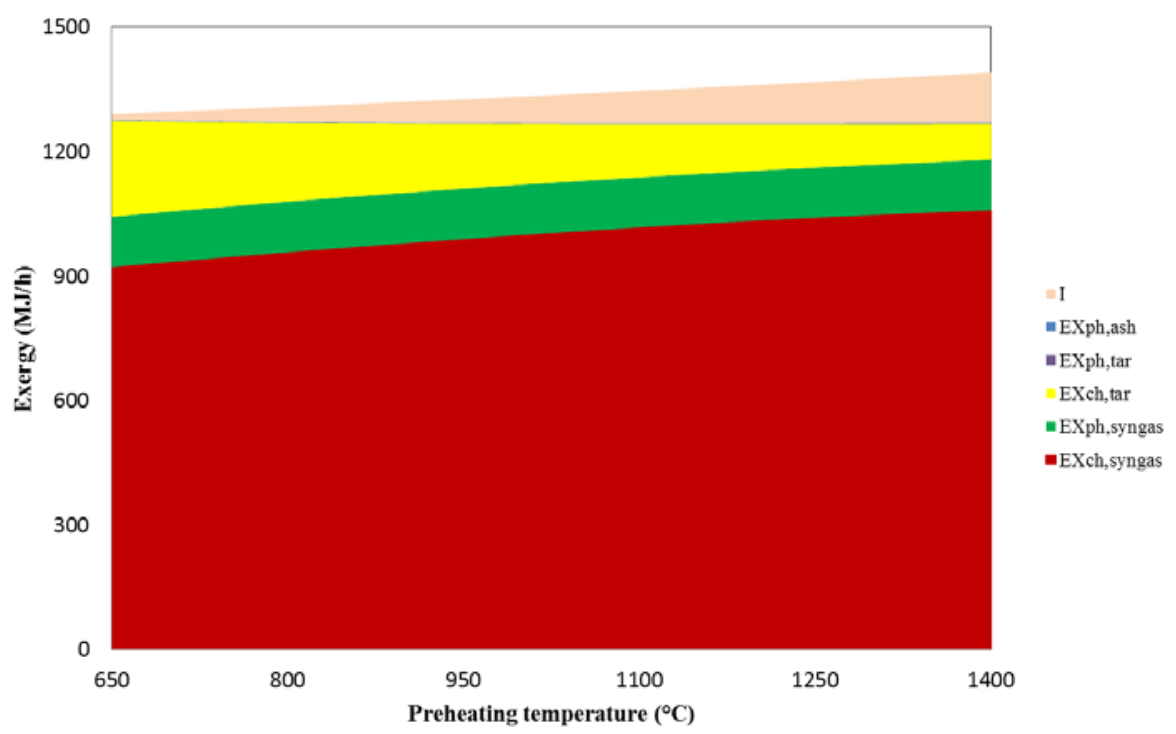

Figure 8. Energy and exergy efficiencies of the HTAG process as a function of preheating temperature for $\mathrm{S} / \mathrm{B}=1$.

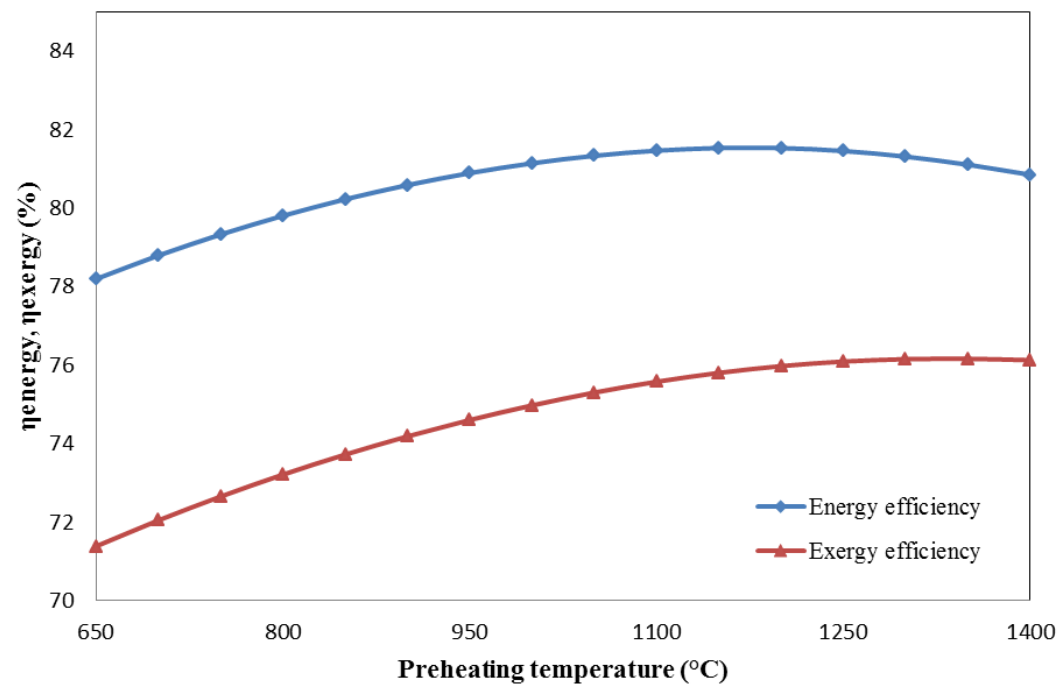

\subsubsection{Operating Regions}

The energy and exergy balances are calculated for 16 different preheating temperatures range from $650{ }^{\circ} \mathrm{C}$ to $1400{ }^{\circ} \mathrm{C}$. And at each preheating temperature, the $\mathrm{S} / \mathrm{B}$ ratios at turning points are found based on the previous discussion in Section 4.2.1. For examples, where the char is completed reacted; the maximum chemical energy is achieved. The similar calculations are also made for 16 different S/B ratios range from 0.5 to 3 . Based on the discussion in the Section 4.2.2, the preheating temperatures at where the maximum energy or exergy efficiencies are achieved are found. In total, more than 350 cases for the combinations of different preheating temperatures with various S/B ratios are considered. As a conclusion, Figure 9 shows the delimitation of the thermodynamically possible conditions for the HTAG system in the preheating temperature-S/B ratio plane. Four curves are plotted: 
$\mathrm{S} / \mathrm{B}_{\text {no char }}=\mathrm{f}(T)$ shows the minimum $\mathrm{S} / \mathrm{B}$ ratio of the HTAG system for complete gasification (no char) for different preheating temperatures as determined by the equilibrium model.

$\mathrm{S} / \mathrm{B}_{\text {maximum }} E_{\text {ch, syngas }}=\mathrm{f}(T)$ shows the $\mathrm{S} / \mathrm{B}$ ratio required to achieve the maximum chemical energy of produced syngas for different preheating temperatures.

$T_{\text {maximum }} \eta_{\text {energy }}=\mathrm{f}(\mathrm{S} / \mathrm{B})$ shows the preheating temperature required to reach the maximum energy efficiency for different $\mathrm{S} / \mathrm{B}$ ratios.

$T_{\text {maximum }} \eta_{\text {exergy }}=\mathrm{f}(\mathrm{S} / \mathrm{B})$ shows the preheating temperature required to reach the maximum exergy efficiency for different $\mathrm{S} / \mathrm{B}$ ratios.

Figure 9. Definition of possible operating regions for the HTAG system.

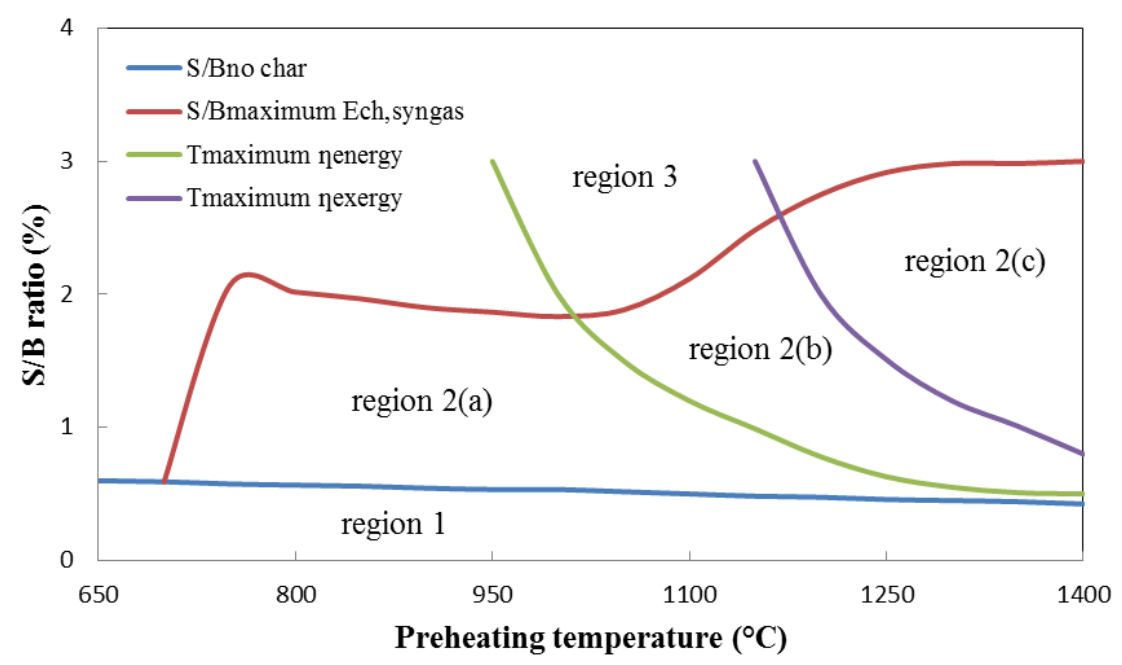

In Region 1, the supplied steam is insufficient for complete char gasification. In contrast, the steam is overfed in Region 3, which means that the efficiency loss cannot be covered by the high chemical achieved energy due to the high S/A ratio in this region. Region 2 presents the possible operating conditions for the HTAG system. The energy and oxygen supplied by steam are enough for the HTAG process; although the efficiencies will decrease for the same preheating temperature with a higher $\mathrm{S} / \mathrm{B}$ ratio, the produced chemical energy increases. Furthermore, for the same S/B ratio, the chemical energy content in the produced syngas has a growing tendency with the increasing preheating temperature. Meanwhile, both of the two efficiencies will increase in Region 2(a). As the preheating temperature continues to increase, the energy efficiency will begin to decrease in Region 2(b), and the exergy efficiency will decrease in Region 2(c). Sum up, Region 2(a) is suggested for industrial operation, from the cost-effective perspective, addition to the relatively high energy and exergy efficiencies.

\section{Conclusions}

A five-step chemical equilibrium model was built for the HTAG process in a downdraft fixed bed gasifier. The simulation results were compared with the experimental data, revealing that the model can predict the performance of the HTAG process with reasonable accuracy. Based on the model, a thermodynamic analysis was conducted based on the first and second laws for various S/B ratios and preheating temperatures of the gasifying agent. 
The S/B ratio has two contradictory effects on the HTAG system: the positive effect of increasing the chemical energy and exergy contents in the product and the negative effect of decreasing the energy and exergy efficiencies. It is important to consider that there is a thermodynamic limitation of the chemical energy of the produced syngas when the S/B ratio reaches 1.83 under the conditions in this study. After this peak point, additional increases in the supplied steam will contribute to only the physical energy of product.

The preheating temperature has a positive effect on both chemical energy (exergy) output and efficiencies. A maximum of $81.5 \%$ of the total energy input can be transferred to the chemical content in the produced syngas when the preheating temperature is $1150{ }^{\circ} \mathrm{C}$, and the peak exergy efficiency is approximately $76.2 \%$ when the gasifying agent is preheated to $1350{ }^{\circ} \mathrm{C}$.

Based on the calculated peak values, a thermodynamically possible operating region was determined. And a practically operating region was suggested for industrial applications.

\section{Conflicts of Interest}

The authors declare no conflict of interest.

\section{References}

1. Pian, C.C.P.; Yoshikawa, K. Development of a high-temperature air-blown gasification system. Bioresour. Technol. 2001, 79, 231-241.

2. Umeki, K.; Yamamoto, K.; Namioka, T.; Yoshikawa, K. High temperature steam-only gasification of woody biomass. Appl. Energy 2010, 87, 791-798.

3. Lucas, C.; Szewczyk, D.; Blasiak, W.; Mochida, S. High-temperature air and steam gasification of densified biofuels. Biomass Bioenergy 2004, 27, 563-575.

4. Jangsawang, W.; Klimanek, A.; Gupta, A.K. Enhanced yield of hydrogen from wastes using high temperature steam gasification. J. Energy Resour. Technol. 2006, 128, 179-185.

5. Ponzio, A.; Kalisz, S.; Blasiak, W. Effect of operating conditions on tar and gas composition in high temperature air/steam gasification (HTAG) of plastic containing waste. Fuel Process. Technol. 2006, 87, 223-233.

6. Lv, P.; Yuan, Z.; Ma, L.; Wu, C.; Chen, Y.; Zhu, J. Hydrogen-rich gas production from biomass air and oxygen/steam gasification in a downdraft gasifier. Renew. Energy 2007, 32, 2173-2185.

7. Delgado, J.; Aznar, M.P.; Corella, J. Biomass gasification with steam in fluidized bed: Effectiveness of $\mathrm{CaO}, \mathrm{MgO}$, and $\mathrm{CaO}-\mathrm{MgO}$ for hot raw gas cleaning. Ind. Eng. Chem. Res. 1997, $36,1535-1543$.

8. Evans, R.; Knight, R.A.; Onischak, M.; Babu, S.P. Process Performance and Environmental Assessment of the Renugas Process. In Energy from Biomass Wastes; Institute of Gas Technology (IGT): Chicago, IL, USA, 1987; pp. 677-694.

9. Wall, G. Exergy flows in industrial processes. Energy 1988, 13, 197-208.

10. Rade, M.; Karamarković, V.M.K.; Jovović, A.; Marasević, M.M.; Lazarević, A.D. Biomass gasification with preheated air: Energy and exergy analysis. Therm. Sci. 2012, 16, 535-550.

11. Karamarkovic, R.; Karamarkovic, V. Energy and exergy analysis of biomass gasification at different temperatures. Energy 2010, 35, 537-549. 
12. Ponzio, A.; Yang, W.; Lucas, C.; Blasiak, W. A Thermodynamic Analysis of High Temperature Agent Gasification (HTAG) Using Biomass and Air. In Proceedings of the 9th Conference on Energy for a Clean Environment, Povoa de Varzim, Portugal, 2-5 July 2007.

13. Zhang, Y.; Li, B.; Li, H.; Liu, H. Exergy Analysis of Biomass Gasification with Steam/Air: A Comparison Study. In Proceedings of the International Conference on Digital Manufacturing and Automation (ICDMA), Changsha, Hunan, China, 18-20 December 2010; pp. 678-681.

14. Fiaschi, D.; Michelini, M. A two-phase one-dimensional biomass gasification kinetics model. Biomass Bioenergy 2001, 21, 121-132.

15. Wang, Y.; Kinoshita, C.M. Kinetic model of biomass gasification. Sol. Energy 1993, 51, 19-25.

16. Nikoo, M.B.; Mahinpey, N. Simulation of biomass gasification in fluidized bed reactor using ASPEN PLUS. Biomass Bioenergy 2008, 32, 1245-1254.

17. Li, X.T.; Grace, J.R.; Lim, C.J.; Watkinson, A.P.; Chen, H.P.; Kim, J.R. Biomass gasification in a circulating fluidized bed. Biomass Bioenergy 2004, 26, 171-193.

18. Puig-Arnavat, M.; Bruno, J.C.; Coronas, A. Review and analysis of biomass gasification models. Renew. Sustain. Energy Rev. 2010, 14, 2841-2851.

19. Atnaw, S.M.; Sulaiman, S.A. Modeling and Simulation Study of Downdraft Gasifier Using Oil-Palm Fronds. In Proceedings of the 3rd International Conference on Energy and Environment, Malacca, Malaysia, 19-23 July 2009.

20. Babu, B.V.; Sheth, P.N. Modeling and simulation of reduction zone of downdraft biomass gasifier: Effect of char reactivity factor. Energy Convers. Manag. 2006, 47, 2602-2611.

21. Giltrap, D.L.; McKibbin, R.; Barnes, G.R.G. A steady state model of gas-char reactions in a downdraft biomass gasifier. Sol. Energy 2003, 74, 85-91.

22. Donaj, P.; Izadpanah, M.R.; Yang, W.; Blasiak, W. Effect of pressure drop due to grate-bed resistance on the performance of a downdraft gasifier. Energy Fuels 2011, 25, 5366-5377.

23. Di Blasi, C.; Signorelli, G.; di Russo, C.; Rea, G. Product distribution from pyrolysis of wood and agricultural residues. Ind. Eng. Chem. Res. 1999, 38, 2216-2224.

24. Boroson, M.L.; Howard, J.B.; Longwell, J.P.; William, A.P. Product yields and kinetics from the vapor phase cracking of wood pyrolysis tars. AIChE J. 1989, 35, 120-128.

25. Sadaka, S.S.; Ghaly, A.E.; Sabbah, M.A. Two phase biomass air-steam gasification model for fluidized bed reactors: Part. I-Model development. Biomass Bioenergy 2002, 22, 439-462.

26. Liinanki, L.; Lindman, N.; Sjöberg, S.-O.; Ström, E. Methane Yield from Biomass Gasification at High Temperature and Pressure. In Fundamentals of Thermochemical Biomass Conversion; Overend, R.P., Milne, T.A., Mudge, K.L., Eds.; Elsevier Applied Science Publishers: London, UK, 1985; pp. 923-936.

27. Balmer, R.T. Thermodynamics; West Publishing Company: St. Paul, MN, USA, 1990.

28. Cengel, Y.A.; Boles, M.A. Thermodynamics: An Engineering Approach; McGraw-Hill Inc.: New York, NY, USA, 1994.

29. Abbott, M.; Van, N. Thermodynamics; McGraw-Hill Book Company: Singapore, 1972.

30. Moran, M.J.; Shapiro, H.N.; Boettner, D.D.; Bailey, M.B. Fundamentals of Engineering Thermodynamics; John Wiley \& Sons, Inc.: New York, NY, USA, 2000.

31. Szargut, J.; Styrilska, T. Approximate evaluation of the exergy of fuels. Brennst. Wärme Kraft 1964, 16, 589-596. (in German) 
32. Stepanov, V.S. Chemical energies and exergies of fuels. Energy 1995, 20, 235-242.

33. Donaj, P. Conversion of Biomass and Waste Using Highly Preheated Agents for Materials and Energy Recovery. In Energy and Furnace Technology; Royal Institute of Technology: Stockholm, Sweden, 2011.

(C) 2014 by the authors; licensee MDPI, Basel, Switzerland. This article is an open access article distributed under the terms and conditions of the Creative Commons Attribution license (http://creativecommons.org/licenses/by/3.0/). 